\title{
RODRIGO DE GRANDIS
}

\section{O DELITO DE INFIDELIDADE PATRIMONIAL E O DIREITO PENAL BRASILEIRO}

Tese de Doutorado

Orientador: Professor Titular Doutor Vicente Greco Filho

UNIVERSIDADE DE SÃO PAULO

FACULDADE DE DIREITO

SÃO PAULO - SP

2018 



\section{O DELITO DE INFIDELIDADE PATRIMONIAL E O DIREITO PENAL BRASILEIRO}

Tese apresentada à Banca Examinadora do Programa de PósGraduação em Direito, da Faculdade de Direito da Universidade de São Paulo, como exigência parcial para obtenção do título de Doutor em Direito, na área de concentração Direito Penal, Medicina Forense e Criminologia, sob a orientação do Professor Titular Doutor Vicente Greco Filho.

UNIVERSIDADE DE SÃO PAULO

FACULDADE DE DIREITO

SÃO PAULO - SP 



\section{Banca Examinadora:}

Prof. Orientador: Vicente Greco Filho

Prof. Examinador:

Prof. Examinador:

Prof. Examinador:

Prof. Examinador:

Prof. Examinador: 

Para Ricardo Masini de Grandis e Theodoro Mansur de Grandis. 



\section{AGRADECIMENTOS}

O trabalho acadêmico pode ser comparado a uma prova de maratona. Da ideia inicial ao primeiro passo da corrida existe um longo período de preparação, dedicação e estudo que o candidato percorre para que ele tenha a aptidão de cruzar a linha de chegada. E nessa jornada nunca se está sozinho. Daí os meus sinceros agradecimentos às pessoas que contribuíram para que este trabalho chegasse, a bom termo, na reta final. Ao Professor Vicente Greco Filho, pela orientação sempre segura e por compartilhar seus enciclopédicos conhecimentos. Ao Professor Renato de Mello Jorge Silveira, por me abrir as portas do “depósito das águas” da Universidade Pompeu Fabra, de Barcelona, e por me apresentar a Professora Nuria Pastor Muñoz, a quem também agradeço pelas pacientes observações dedicadas à minha pesquisa. Ainda da Pompeu Fabra, a minha gratidão à Ana Carolina Oliveira, pela sempre frutífera troca de ideias e pelo apoio logístico em Barcelona. Da Alemanha, Luís Greco e Alaor Leite me incentivaram a estudar a Untreue e forneceram preciosas sugestões bibliográficas. Rafael Mafei Rabelo Queiroz foi fundamental nas orientações metodológicas. Minha gratidão à amiga Heloisa Estellita pelo estímulo constante, e aos parceiros de pós-graduação João Daniel Rassi, Marcelo Costenaro Cavali e Matheus Falivene pelas sempre profícuas conversas e sincera amizade. À Lucia Lopes Mansur, minha sogra, por cuidar do neto Theo enquanto eu escrevia. Por fim, meu carinhoso agradecimento à minha esposa, Carolina Mansur da Cunha de Grandis, diante do apoio incondicional e por acompanhar, lado a lado, todo o processo de elaboração desta tese. Literalmente. 

"Que me pesa que ninguém leia o que escrevo? Escrevo-me para me distrair de viver, e publico-me porque o jogo tem essa regra. Se amanhã se perdessem todos os meus escritos, teria pena, mas, creio bem, não uma pena violenta e louca como seria de supor, pois que em tudo isso ia toda a minha vida" (Fernando Pessoa, na voz de Bernardo Soares. Livro do desassossego). 



\section{RESUMO}

A presente tese de doutoramento investiga a necessidade de criação do crime de infidelidade patrimonial (Untreue), e as subsequentes repercussões derivadas dessa proposta no Direito Penal brasileiro. Em síntese, a infidelidade patrimonial incrimina o comportamento do indivíduo que, tendo um dever de proteção do patrimônio alheio, causalhe dolosamente um dano mediante a quebra desse dever. Sob o ponto de vista políticocriminal são estudadas as lacunas de punibilidade e a insuficiente proteção penal de interesses patrimoniais pelos crimes atualmente previstos no ordenamento brasileiro. Sob os parâmetros da dogmática penal, analisam-se os requisitos necessários à adequada configuração do delito de infidelidade patrimonial. O estudo se inicia com a verificação dos modelos de incriminação da infidelidade patrimonial mediante exame de Direito Comparado, passando-se, em seguida, à análise do conteúdo do injusto sobre o qual se baseia a Untreue. Ato contínuo, são realizadas considerações dogmáticas sobre a estrutura fundamental da infidelidade patrimonial, com ênfase no bem jurídico tutelado (patrimônio) e nas várias concepções teóricas que procuram estabelecer um conceito de patrimônio para o Direito Penal. Ultimada a pesquisa sobre os principais requisitos do delito de infidelidade, o estudo aborda algumas manifestações implícitas da Untreue no ordenamento jurídico nacional, e como a apreensão parcial do injusto da infidelidade patrimonial tem proporcionado fricções com o princípio da legalidade e com a proibição da analogia in malam partem. Por fim, diante da constatação de uma insuficiente tutela penal e da existência de diversas lacunas de punibilidade, propõe-se a tipificação do crime de infidelidade patrimonial no ordenamento jurídico brasileiro, e, em consequência, a necessidade de uma ampla descriminalização e decorrente readequação do sistema penal de proteção ao patrimônio que se encontra legitimamente sob o poder de outrem.

Palavras-chave: Crime; Injusto penal; Infidelidade; Confiança; Patrimônio; Administração de patrimônio alheio; Lacunas de punibilidade; Princípio da legalidade; Direito Penal Econômico. 



\begin{abstract}
The current doctoral thesis investigates the need for the establishment of the crime regarding asset management unfaithfulness (Untreue), and its subsequent effects derived from such proposal in Brazilian Criminal Law. In summary, asset management unfaithfulness incriminates the behavior of the person who, having a duty to protect the asset of another person, intently causes damage or loss by breaching such duty. Within the political-criminal point of view, the paper assesses the loopholes of punishment and the insufficient criminal protection over patrimonial interests, absent in the array of crimes currently predicted under Brazilian Law. Touching the meaning of dogmatic Criminal Law, the necessary requirements are analyzed to its proper configuration concerning the crime of asset management unfaithfulness. The study begins with the ascertainment of incriminatory standards of asset unfaithfulness by means of an exam upon Comparative Law, then, moving on to the content analysis regarding the unfair reason over which is the basis of Untreue. Throughout the thesis, dogmatic considerations are proposed on the fundamental structure of asset management unfaithfulness, emphasizing the protected legal good (asset) and the several theories and concepts that attempt to establish a concept of asset to Criminal Law. Having concluded the research over the main requirements of such crime of unfaithfulness, the study addresses some implicit manifestations of Untreue in national Law and how a partial seizure of the unfair amount in the asset management unfaithfulness crime has provided conflict with the legality principle and with the prohibition of the analogy in malam partem. Finally, having proved an insufficient criminal guardianship rule and the existence of several loopholes of punishment, it proposes the classification of the crime of asset management unfaithfulness in Brazilian Legal System, and, consequently, the need for a widened decriminalization and consequent readjustment of criminal system for the asset protection that is lawfully under the power of another person.
\end{abstract}

Keywords: Crime; Criminal unfair reason; Unfaithfulness; Reliance; Asset; management of another person's asset; Loopholes of punishment; Legality principle; Economic Criminal Law. 



\section{SOMMARIO}

Questa tesi di dottorato si propone di indagare se sia necessario creare il reato di infedeltà patrimoniale (Untreue) e di studiare le successive ripercussioni derivanti da questa proposta nel diritto penale brasiliano. In sintesi, il reato di infedeltà patrimoniale incrimina il comportamento di un individuo che, pur avendo un dovere di protezione del patrimonio altrui, causa dolosamente un danno a tale patrimonio in violazione del suo dovere. Dal punto di vista politico-criminale, sono studiate le lacune per quanto riguarda la punibilità e l'insufficiente protezione penale degli interessi patrimoniali per i reati attualmente previsti nel sistema giuridico brasiliano. Per quanto riguarda la dogmatica penale, sono analizzati i requisiti necessari per la corretta configurazione del reato di infedeltà patrimoniale. Lo studio inizia con l'analisi dei modelli di incriminazione della fattispecie di infedeltà patrimoniale attraverso uno studio di diritto comparato e, in seguito, si concentra sull'analisi del contenuto dell'ingiusto su cui si fonda l'Untreue. Subito dopo, sono realizzate delle considerazioni dogmatiche sulla struttura fondamentale della infedeltà patrimoniale, con particolare attenzione al bene giuridico protetto (patrimonio) e alle varie teorie che cercano di stabilire un concetto di patrimonio valido nel diritto penale. Finalizzato alla investigazione dei principali requisiti del reato di infedeltà, lo studio affronta alcune manifestazioni implicite di Untreue nell'ordinamento giuridico nazionale e valuta come l'apprensione parziale dell'ingiusto del reato di infedeltà patrimoniale sia in contrasto con il principio di legalità e di analogia in malam partem. Infine, a fronte della constatazione di un'insufficiente protezione penale e dell'esistenza di diverse lacune di punibilità, si propone la tipizzazione del reato di infedeltà patrimoniale nell'ordinamento giuridico brasiliano, e, di conseguenza, la necessità di un'ampia depenalizzazione e conseguente riordinamento del sistema penale di protezione del patrimonio posto legittimamente sotto il potere altrui.

Parole chiave: Reato; Ingiusto penale; Infedeltà; Fiducia; Patrimonio; Gestione del patrimonio altrui; Lacune di punibilità; Principio di legalità; Diritto Penale Economico. 



\section{SUMÁRIO}

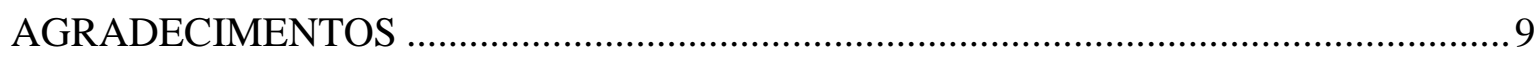

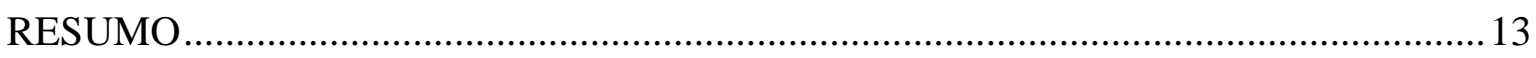

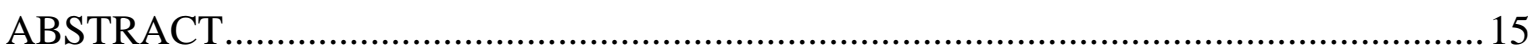

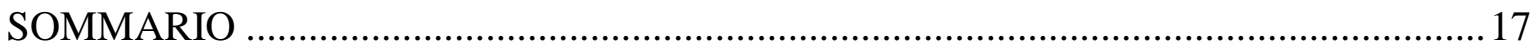

INTRODUÇÃ

A escolha do tema: por que infidelidade patrimonial? .................................................2.

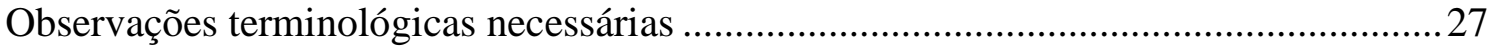

1. MODELOS DE INCRIMINAÇÃO DA INFIDELIDADE PATRIMONIAL ................29

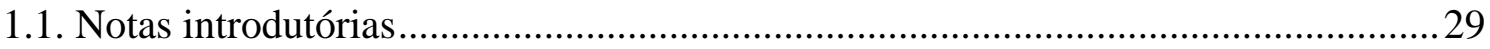

1.2. Infidelidade patrimonial como tipo penal genérico ............................................. 30

1.3. Infidelidade patrimonial como delito societário ................................................... 37

1.4. Infidelidade patrimonial como "tipo conjugado" ............................................... 44

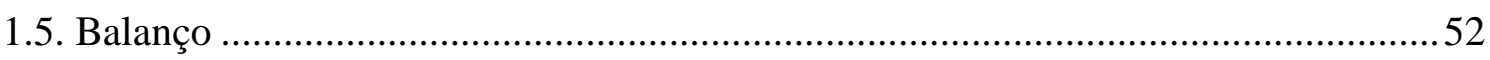

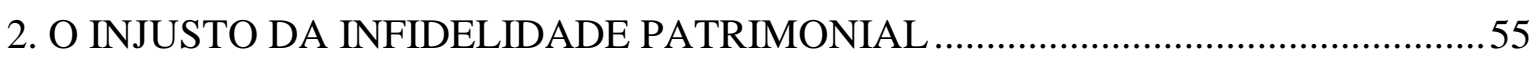

2.1. O injusto do crime de infidelidade patrimonial ................................................55

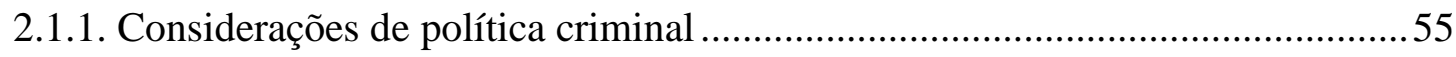

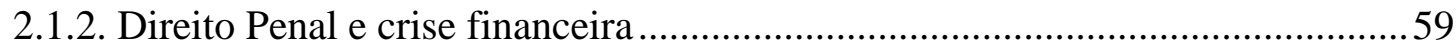

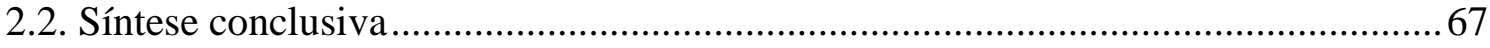

3. CONSIDERAÇÕES DOGMÁTICAS SOBRE O DELITO DE INFIDELIDADE

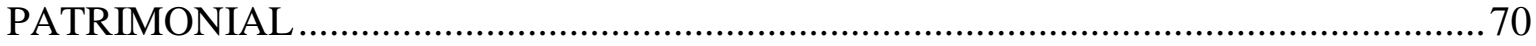

3.1. O bem jurídico do delito de infidelidade patrimonial ............................................ 70

3.1.1. O conceito de patrimônio no delito de infidelidade patrimonial ....................... 72

3.1.1.1. A concepção jurídica de patrimônio .............................................................. 73

3.1.1.2. A concepção econômica do patrimônio ...................................................... 76 
3.1.1.3. A concepção mista jurídico-econômica do patrimônio e seus critérios corretivos.

3.1.1.4. A concepção pessoal e a concepção funcional do patrimônio .83

3.1.1.4.1. Concepção pessoal de patrimônio: aplicação às pessoas jurídicas? ....87

3.1.1.5. A concepção dinâmica do patrimônio: breves considerações .89

3.1.2. A alteridade do patrimônio no crime de infidelidade patrimonial .....................91

3.1.3. Conceito de patrimônio no Direito Penal brasileiro .94

3.1.4. Conclusão: qual o conceito de patrimônio do crime de infidelidade patrimonial? .98

3.2. Sujeito ativo e sujeito passivo do crime de infidelidade patrimonial 112

3.2.1. Sujeito ativo 112

3.2.2. Sujeito passivo 116

3.3. Fontes do dever de garante no crime de infidelidade patrimonial 119

3.4. Conteúdo do dever de garante no crime de infidelidade patrimonial 123

3.5. Questões de autoria e de participação no crime de infidelidade patrimonial..........128

3.5.1. Introdução: delitos de domínio e delitos de infração de dever 128

3.5.2. Infidelidade patrimonial como infração de dever ou delito de domínio? 134

3.6. A ação típica do crime de infidelidade patrimonial 140

3.6.1. Comportamentos comissivos e omissivos (impróprios) na infidelidade patrimonial 142

3.7. O risco permitido no delito de infidelidade patrimonial ......................................153

3.7.1. Realização de negócios de risco ou especulativos ..........................................163

3.8. O elemento subjetivo do crime de infidelidade patrimonial ..................................168

3.9. A relevância do dano patrimonial no crime de infidelidade patrimonial................174

3.9.1. A consumação do crime de infidelidade patrimonial.....................................178

3.9.2. A tentativa do crime de infidelidade patrimonial..........................................183

4. MANIFESTAÇÕES “IMPLÍCITAS” DE INFIDELIDADE PATRIMONIAL NO DIREITO PENAL BRASILEIRO 
4.1. Considerações prévias.

4.2. Infidelidade patrimonial e os crimes contra o patrimônio no Direito Penal brasileiro 188

4.2.1. Infidelidade patrimonial e apropriação indébita 188

4.2.2. Infidelidade patrimonial e estelionato 193

4.2.3. Infidelidade patrimonial e o delito de fraudes e abusos na fundação ou administração de sociedade por ações 195

4.3. Infidelidade patrimonial e peculato 199

4.4. Infidelidade patrimonial e o delito de emprego irregular de verbas ou rendas públicas 203

4.5. Infidelidade patrimonial e os crimes contra o sistema financeiro nacional 204

4.5.1. Notas introdutórias sobre a Lei n. 7.492/1986 204

4.5.2. Infidelidade patrimonial e a gestão fraudulenta e temerária de instituição financeira 206

4.5.3. Infidelidade patrimonial e o delito de "apropriação indébita financeira" ........215

4.5.4. Infidelidade patrimonial e o delito de "caixa dois" ........................................224

4.5.5. Infidelidade patrimonial e o delito de empréstimo vedado..............................228

4.6. Conclusão: a necessidade de criação da infidelidade patrimonial brasileira ..........233

5. PROPOSTA PARA TIPIFICAÇÃO DO CRIME DE INFIDELIDADE PATRIMONIAL

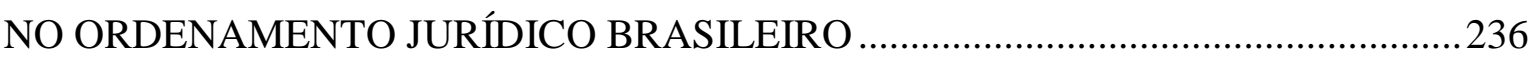

5.1. Considerações gerais acerca da elaboração de tipos penais ..................................2236

5.2. Requisitos dogmáticos do delito de infidelidade patrimonial brasileiro.................241

5.2.1. Elementos objetivos do delito de infidelidade patrimonial brasileiro .............244

5.2.1.1. A ação típica do delito de infidelidade patrimonial brasileiro..................247

5.2.1.2. O resultado do delito de infidelidade patrimonial brasileiro ...................248

5.2.2. Elemento subjetivo do delito de infidelidade patrimonial brasileiro ................250

5.2.3. As penas do delito de infidelidade patrimonial brasileiro ............................ 252

5.3. A ação penal do delito de infidelidade patrimonial brasileiro 257 
5.4. A competência para o processo do delito de infidelidade patrimonial brasileiro ...260

5.5. Proposta de revogação e derrogação de tipos penais brasileiros .261

5.5.1. Da preservação (e reinterpretação) do crime de apropriação indébita... .262

5.5.2. Da derrogação do crime do art. 177 do Código Penal .263

5.5.3. Da revogação do crime de gestão fraudulenta e temerária de instituição financeira .265

5.5.4. Da derrogação do crime de "apropriação indébita financeira" .267

5.5.5. Da revogação do crime de "caixa dois" .268

CONCLUSÃO .271

REFERÊNCIAS .275 


\section{INTRODUÇÃO}

\section{A escolha do tema: por que infidelidade patrimonial?}

A presente tese de doutorado tem como objeto o delito de infidelidade patrimonial, e, em síntese, pretende analisar a necessidade de sua criação no Direito Penal brasileiro. Em linhas gerais, o delito tipifica a conduta do sujeito que, ostentando um dever de proteção do patrimônio alheio, causa-lhe um dano mediante a quebra desse dever.

O delito de infidelidade patrimonial tem previsão em diversos ordenamentos jurídicos estrangeiros, como na Alemanha (Untreue ${ }^{1}$ ), Itália (infedeltá patrimoniale ${ }^{2}$ ), Espanha (administración desleal ${ }^{3}$ ) e Portugal (infidelidade ${ }^{4}$ ), voltando-se à proteção penal do patrimônio. Na Alemanha, por exemplo, o tipo penal de infidelidade patrimonial tem sido utilizado para viabilizar a imputação penal de condutas atreladas a doações a partidos políticos, à concessão de vantagens indevidas a particulares, ao pagamento de bônus excessivos aos administradores da pessoa jurídica, à criação de "caixa dois" na companhia e aos "negócios especulativos de alto risco", fundamentando, inclusive, a penalização dos responsáveis pela crise financeira de 2008, que acarretou a quebra do banco norte-americano

${ }^{1} \S 266$ do Código Penal (StGB) (tradução livre): Aquele que abusa da faculdade de dispor sobre o patrimônio alheio ou de obrigar a outro que lhe tenha sido outorgado por lei, mandato de autoridade ou negócio jurídico, ou lesione o dever de salvaguardar interesses patrimoniais alheios que lhe incumbem em razão de lei, mandado de autoridade, negócio jurídico ou relação de fidelidade e, desse modo, cause um prejuízo àquele cujos interesses patrimoniais tinha que proteger, será punido com pena privativa de liberdade de até cinco anos ou com pena de multa.

${ }^{2}$ Artigo 2634 do Código Civil (tradução livre): Os administradores, os diretores-gerais e os liquidantes que, tendo um interesse em conflito com o da sociedade visando para si ou para outrem um injusto lucro ou outro benefício, realizar ou concorrer à deliberação de atos de disposição de bens sociais, causando intencionalmente à sociedade um prejuízo patrimonial, serão punidos com reclusão de seis meses a três anos. A mesma é aplicável se o fato é cometido em relação a bens detidos ou geridos pela sociedade em nome de terceiros, causando a estes um dano patrimonial.

${ }^{3}$ Artigo 252 do Código Penal (tradução livre): Serão puníveis com as penas do artigo 249 ou, em seu caso, do artigo 250, aqueles que tendo poderes para administrar um patrimônio alheio, emanados de lei, atribuídos pela autoridade ou assumidos mediante um negócio jurídico, os infrinjam excedendo-se no exercício delas, e desse modo causem um prejuízo ao patrimônio administrado. Se a quantia do prejuízo patrimonial não exceder 400 euros, se imporá uma pena de multa de um a três meses.

${ }^{4}$ Artigo $224^{\circ}$ do Código Penal: 1 - Quem, tendo-lhe sido confiado, por lei ou por acto jurídico, o encargo de dispor de interesses patrimoniais alheios ou de os administrar ou fiscalizar, causar a esses interesses, intencionalmente e com grave violação dos deveres que lhe incumbem, prejuízo patrimonial importante é punido com pena de prisão até 3 anos ou com pena de multa. 2 - A tentativa é punível. 3 - O procedimento criminal depende de queixa. 4 - É correspondentemente aplicável o disposto no artigo $206^{\circ}$ e na alínea a) do artigo $207^{\circ}$. 
Lehman Brothers e a operação de resgate da seguradora American International Group pelo Federal Reserve dos Estados Unidos da América.

A relevância acadêmica do tema é proclamada à unanimidade pela doutrina estrangeira: Bernd Schünemann vislumbra na Untreue o delito econômico por excelência do nosso tempo". Para Luís Greco, trata-se do "dispositivo central do direito penal econômico alemão"6, enquanto Silva Sánchez, ainda mais enfático, reputa-o como o "paradigma do delito do presente e do futuro" ". Até pela perspectiva da corporate governance, registram Foffani e Nieto Martín, existe a tendência a atribuir ao crime de infidelidade patrimonial um "papel promocional", ou seja, um instrumento jurídico chamado a favorecer a implementação de uma nova e mais rigorosa ética nos negócios, especificamente na esfera da administração das empresas ${ }^{8}$. Aliás, registre-se que foi justamente sob o âmbito de incidência do delito de infidelidade patrimonial que diversos casos relacionados à má ou abusiva gestão de sociedades empresárias na Alemanha foram penalmente dirimidos, como os rumorosos casos Mannesmann-Vodafone e Siemens.

Não obstante, no ordenamento jurídico brasileiro não se vislumbra semelhante tutela $^{9}$, constatando-se, ao revés, a inexistência de figuras delitivas com a aptidão para apreender a integralidade do injusto penal da administração desleal e proteger adequadamente o patrimônio alheio, aqui considerado em sentido global, isto é, para além da coisa alheia móvel e corpórea que constitui, por exemplo, o objeto material do crime de apropriação indébita (art. 168 do Código Penal brasileiro), ou, no máximo, infrações penais que apenas tangenciam a ideia de infidelidade patrimonial consolidada no Direito comparado, como sucede com o delito delineado no art. 177, § $1^{\circ}$, do Código Penal (Fraudes

${ }^{5}$ SCHÜNEMANN, Bernd. La administración desleal de los órganos societarios: el caso Mannesmann. In: GÓMEZ-JARA DÍEZ, Carlos; GARCÍA CAVERO, Percy (Ed.). La administración desleal de los órganos societarios. Perú: Ara Editores, 2010. p. 15.

${ }^{6}$ SCHÜNEMANN, Bernd. A chamada "crise financeira": falha sistêmica ou criminalidade globalmente organizada. In: GRECO, Luís (Coord.). Estudos de direito penal, direito processual penal e filosofia do direito. São Paulo: Marcial Pons, 2013. p. 7.

${ }^{7}$ SILVA SÁNCHEZ, Jesús-María. Fundamentos del derecho penal de la empresa. Buenos Aires: B de F, 2013. p. 11.

${ }^{8}$ FOFFANI, Luigi; NIETO MARTÍN, Adán. Corporate governance y administración desleal: casos y problemas de derecho comparado europeo. Revista Penal, n. 17, 2006, España: Tirant lo Blanch. p. 113.

${ }^{9}$ Note-se, em ordem a demonstrar a inexistência da tipificação penal da infidelidade patrimonial no Brasil, que o Supremo Tribunal Federal tem rejeitado pedidos de extradição com capitulação jurídica na Untreue, valendo-se, como fundamento, da inexistência de dupla tipicidade: Extradição n. 377, Rel. Min. Moreira Alves; Extradição n. 682-7, Rel. Min. Francisco Rezek; Extradição n. 789-1, Rel. Min. Maurício Corrêa. Contra: Extradição n. 1.078-6, Rel. Min. Gilmar Mendes. 
e abusos na fundação ou administração de sociedades por ações), incidente exclusivamente sobre as condutas praticadas no âmbito das sociedades por ações, e o crime do art. $4^{\circ}$ da Lei n. 7.492/1986 (gestão fraudulenta e temerária), porquanto aplicável somente aos comportamentos fraudulentos e/ou temerários levados a efeito pelos controladores e administradores no contexto das instituições financeiras.

Ainda na Parte Especial do Código Penal configuram exemplos palpáveis dessa captação incompleta os delitos de peculato-desvio (art. 312) e de emprego irregular de verbas públicas (art. 315). Na legislação especial também é possível constatar outras manifestações fragmentárias de infidelidade, as quais atingem, em certa medida, o patrimônio, como sucede com o desvio de bens e valores (art. $5^{\circ}$ da Lei n. 7.492/1986) e com o denominado delito de empréstimos vedados (art. 17 da Lei n. 7.492/1986).

A lacuna de punibilidade torna-se ainda mais evidente quando se tem presente a perpetração de agressões ao patrimônio alheio no ambiente do Direito Societário que não se inserem no raio de proteção dos tipos penais supramencionados, notadamente as sociedades limitadas, ou quando a administração infiel do patrimônio de terceiro ocorre por intermédio de uma pessoa física sem que ela se constitua verdadeiramente em apropriação para si ou outrem pela ausência do ânimo de dono.

As implicações práticas são, pois, inegáveis. É conhecida a relevância, na atualidade, das sociedades empresárias no desenvolvimento da economia, marcada pelo desmembramento entre a titularidade das ações e a administração da sociedade. Na mesma medida, contudo, tem-se notado uma imensa gama de manobras no ambiente corporativo que atingem diretamente o patrimônio de acionistas e outras pessoas físicas ou jurídicas lesadas com a abusiva ou infiel gestão dos administradores, a ponto de essas manobras despertarem a atenção do Direito Penal, sobretudo do Direito Penal Econômico.

Sob esse contexto, a análise da jurisprudência brasileira e a leitura de algumas acusações criminais vazadas principalmente no âmbito do Direito Penal Econômico revelam que diversas condutas infiéis têm sido penalmente punidas de modo indevido pelo Poder Judiciário, em especial por intermédio de algumas manifestações setoriais de infidelidade na legislação penal brasileira, o que tem ensejado algumas distorções dogmáticas em razão do manejo de figuras penais que, ao menos sob o ponto de vista da tipicidade estrita, não se amoldam perfeitamente à conduta concretamente praticada, gerando, com isso, uma clara violação do princípio da legalidade. 
Tudo isso, porém, foi paradoxalmente insuficiente para chamar a atenção do ambiente acadêmico brasileiro. De fato, à exceção da obra de Paulo José da Costa Jr., que, em conjunto com Cesare Pedrazzi, já apontava, em 1973, a aparente lacuna das legislações de tipo latino, como o nosso, que não conheciam a figura genérica da infidelidade patrimonial $^{10}$, e, mais recentemente, dos estudos de Nilo Batista ${ }^{11}$ e de Miguel Reale Jr. ${ }^{12}$, a doutrina nacional parece simplesmente ter ignorado a Untreue.

Nem mesmo a Comissão de Juristas encarregada da elaboração de Anteprojeto de Código Penal, criada pelo Requerimento n. 756/2011, do Senador da República Pedro Taques, apercebeu-se do tema, a despeito da citada ampla e notória discussão europeia, e do fato de o Brasil figurar como signatário da Convenção das Nações Unidas contra a Corrupção (Convenção de Mérida), internalizada por intermédio do Decreto n. 5.687/2006, cujo art. 22, ao tratar da Malversação ou peculato de bens no setor privado, conclama cada Estado a considerar "a possibilidade de adotar medidas legislativas e de outras índoles que sejam necessárias para qualificar como delito, quando cometido intencionalmente no curso de atividades econômicas, financeiras ou comerciais, a malversação ou peculato, por uma pessoa que dirija uma entidade do setor privado ou cumpra qualquer função nela, de quaisquer bens, fundos ou títulos privados ou de qualquer outra coisa de valor que se tenha confiado a essa pessoa por razão de seu cargo".

Essa inércia não foi alterada em razão de alguns acontecimentos recentes envolvendo as pessoas jurídicas Alstom, Siemens e Petrobras, os quais evidenciam a necessidade de pesquisar o crime de infidelidade patrimonial em função da citada lacuna de punibilidade e da percepção de que ele representa um injusto penal que não tem sido suficientemente apreendido pelas infrações penais vigentes no ordenamento brasileiro.

A presente tese tem, portanto, dois eixos principais. Sob a perspectiva do ordenamento jurídico posto, ou seja, de lege data, a tese caminhará no sentido de que o injusto típico da infidelidade patrimonial representa uma importante ferramenta na releitura de tipos penais que, de algum modo, apresentam alguns traços ou vestígios de infidelidade.

\footnotetext{
${ }^{10}$ PEDRAZZI, Cesare; COSTA JR., Paulo José da. Tratado de direito penal econômico: direito penal das sociedades anônimas. São Paulo: RT, 1973. v. I. p. 180.

${ }^{11}$ BATISTA, Nilo. Empréstimos ilícitos na Lei 7.492/86. In: PODVAL, Roberto (Org.). Temas de direito penal econômico. São Paulo: RT, 2000. p. 320-321.

12 REALE, Miguel; REALE JÚNIOR, Miguel; FERRARI, Eduardo Reale. Dever de lealdade do administrador na empresa e direito penal. In: Experiências do direito. Campinas: Millenium Editora, 2004. p. 233 e ss.
} 
De lege ferenda, analisar-se-á a necessidade de criação do crime de infidelidade patrimonial no Brasil, contemplando-se, em consequência, as justificativas de política criminal que sustentariam a implementação da versão brasileira de Untreue, bem como o estudo dogmático de todos os requisitos típicos do crime (bem jurídico, sujeito ativo, sujeito passivo, comportamento típico, elemento subjetivo e resultado), e a natureza da ação penal mais adequada, isto é, se a persecução penal mais eficiente para o crime de infidelidade patrimonial dar-se-á por intermédio de ação penal pública (incondicionada ou condicionada) ou de ação penal de iniciativa privada (queixa-crime).

Destaque-se, contudo, que a proposta de criação de uma infidelidade patrimonial brasileira não se limitará apenas ao reconhecimento de uma lacuna de punibilidade no ordenamento pátrio, mas à indicação de que a ausência de uma figura penal que apreenda com exatidão o conteúdo do injusto da administração desleal tem suscitado fricções concretas com o princípio constitucional da legalidade e com a proibição da analogia in malam partem. Por conseguinte, a proposta contida na tese não se circunscreverá à simples e inconsequente criação de mais um tipo penal, contemplando, igualmente, a possibilidade de uma ampla descriminalização e a decorrente readequação do sistema penal de proteção ao patrimônio, com ênfase nas condutas perpetradas no âmbito do Direito Penal Econômico. Evita-se, assim, o fenômeno da "proliferação hipertrófica de tipos" de que recentemente têm padecido os crimes contra o patrimônio ${ }^{13}$.

\section{Observações terminológicas necessárias}

Enquanto manifestação jurídico-penal internacional, o delito que consubstancia o objeto deste estudo ostenta várias denominações legais, as quais podem genericamente ser traduzidas, neste momento, como infidelidade patrimonial, deslealdade patrimonial, administração desleal e administração infiel. A diversidade de nomen juris, porém, não significa que estejamos diante de fenômenos substancialmente diferentes, e nem é suficiente para ocultar a essência do delito, porquanto atrelada indissociavelmente à necessidade de dano patrimonial efetivo mediante uma prévia violação do dever de proteção assumido faticamente sobre o patrimônio de terceiro.

\footnotetext{
${ }^{13}$ SALVADOR NETTO, Alamiro Velludo. Direito penal e propriedade privada: a racionalidade do sistema penal na tutela do patrimônio. São Paulo: Atlas, 2014. p. 26-27.
} 
Nesse sentido, o termo “infidelidade patrimonial”, tradução normalmente empregada para o delito alemão de $U_{n t r e u e^{14}}$, parece ter o mérito de apreender, com uma dose maior de precisão, o injusto que fundamenta esta infração penal, sobretudo porque ele de antemão indica em seu frontispício o objeto de proteção penal (patrimônio) ${ }^{15}$.

Não obstante, ainda que assumamos que "todas as palavras que usamos para falar do mundo que nos rodeia, e de nós mesmos, são, ao menos, potencialmente vagas"16, em ordem a evitar indesejáveis confusões terminológicas, advertimos, desde já, que o presente estudo designará o objeto pesquisado indistintamente como infidelidade patrimonial, administração desleal, administração infiel e, finalmente, Untreue, sem adotar qualquer posição sobre a (in)conveniência da adoção de tal ou qual denominação.

\footnotetext{
${ }^{14}$ SCHÜNEMANN, Bernd. A chamada “crise financeira”, cit., p. 14.
}

${ }^{15}$ Nesse sentido, por exemplo, LEITE, Alaor; TEIXEIRA, Adriano. O principal delito econômico da moderna sociedade industrial: observações introdutórias sobre o crime de infidelidade patrimonial. Revista do Instituto Brasileiro de Direito Penal Econômico, n. 1, Org. Luiz Antonio Câmara, Bibiana Fontella, Florianópolis: Empório do Direito, 2017. p. 31.

${ }^{16}$ CARRIÓ, Genaro R. Notas sobre derecho y lenguaje. 5. ed. Buenos Aires: Abeledo-Perrot, 2006. p. 34. 


\section{CONCLUSÃO}

Da presente investigação podem ser extraídas as seguintes conclusões:

1. O injusto que fundamenta a criminalização da infidelidade patrimonial baseia-se na quebra do dever de proteção derivado da posição de garante assumida pelo administrador em face do patrimônio pertencente a um terceiro.

2. A ruptura da relação de fidúcia ou confiança estabelecida entre o administrador e o dono do patrimônio administrado corporifica apenas o meio ou instrumento através do qual o sujeito ativo comete a agressão patrimonial.

3. O que gera o dever de o administrador servir fielmente é a ampla capacidade de dispor dos bens de outrem à semelhança deste, ou seja, o poder concreto de controlar, de modo abrangente e sem intensa fiscalização, a esfera jurídica alheia.

4. Os deveres que incidem sobre o administrador do patrimônio alheio são abrangentes: refletem tanto deveres positivos voltados a uma atuação que incremente o patrimônio gerido como deveres negativos, os quais impõem a abstenção de qualquer comportamento com a potencialidade de produzir um prejuízo patrimonial.

5. O Direito Penal não pode ficar alheio às crises financeiras. Ainda que complexas ou sofisticadas, as condutas que ensejam a eclosão das crises econômicas são obra do ser humano e, nessa condição, são reconduzíveis a uma pessoa ou grupo de pessoas perfeitamente individualizáveis. Daí a necessidade de regramento penal na resolução dos casos considerados mais graves sem que se desnaturem as clássicas categorias de responsabilização criminal, enfatizando-se a posição de salvaguarda ou de garante daquele que exerce faticamente o poder de administrar o patrimônio de outrem.

6. O estudo dos modelos estrangeiros de incriminação da Untreue revela a necessidade de criação de, pelo menos, um "tipo genérico" de infidelidade patrimonial localizado entre os crimes contra o patrimônio da Parte Especial do Código Penal.

7. O delito de infidelidade patrimonial previsto como "tipo genérico" tem a aptidão de regular tanto as agressões patrimoniais mais singelas como as mais sofisticadas manobras praticadas no contexto de grandes corporações financeiras, assumindo, por conseguinte, uma posição de destaque no Direito Penal Econômico. 
8. A concepção pessoal-funcional do patrimônio é a que melhor se adapta ao delito de administração desleal, na medida em que o dano patrimonial fica condicionado ao desvio ou à frustração das expectativas e finalidades assumidas por ocasião da gestão do patrimônio alheio com alguma potencialidade econômica.

9. Os fins perseguidos pelo titular do patrimônio compõem a relação interna criada com o administrador. Assim, eles necessariamente devem ser valorados na apreciação do risco permitido que sustentará a imputação penal no plano objetivo.

10. Não existe óbice para a compreensão do delito de infidelidade patrimonial como um comportamento omissivo impróprio ou comissivo por omissão.

11. O Brasil não possui um tipo penal capaz de apreender o injusto dos comportamentos que agridem o patrimônio "a partir de dentro", ou seja, por quem o tenha recebido com dever de proteção sob o contexto de uma relação jurídica de administração.

12. O Brasil contempla infrações penais que, em maior ou menor medida, a depender de seu lastro político-criminal e de sua configuração dogmática, apenas tangenciam o injusto do delito de infidelidade patrimonial, captando-o parcialmente.

13. A ausência do tipo penal de infidelidade patrimonial no Brasil e a apreensão parcial do injusto por outros tipos penais ensejam violações do princípio da legalidade e da proibição da analogia in malam partem. A necessidade de resposta penal a uma situação concreta convida o aplicador da norma a estender os requisitos dogmáticos de outros delitos com conteúdo patrimonial que não captam a essência da Untreue.

14. A lacuna de punibilidade também pode ser verificada em relação ao patrimônio das pessoas jurídicas, pois o ordenamento jurídico brasileiro não contempla infrações penais com a aptidão de tutelar todas as modalidades societárias existentes.

15. O legislador brasileiro ignora que as agressões patrimoniais não se restringem às instituições financeiras; a proteção penal do patrimônio social e do funcionamento em conformidade com os fins estipulados das demais espécies de pessoas jurídicas representam elementos de fundamental importância na sociedade capitalista.

16. Impõe-se a criação do crime de administração desleal no Brasil para colmatar as lacunas de punibilidade, promover uma eficaz implementação do sistema penal de proteção ao patrimônio quando a agressão partir de quem tem o dever de protegê-lo e impedir que o aplicador da norma penal incriminadora lance mão de analogias, interpretações analógicas, 
interpretações extensivas e outros subterfúgios hermenêuticos que, mercê de atenderem a um chamado de justiça material e equidade para a resolução de uma situação concreta, frequentemente atentam contra o princípio da legalidade penal.

17. Propomos que seja criada a seguinte infidelidade patrimonial:

Art. 168-B. Abusar dos poderes de administração de um patrimônio alheio que lhe foram incumbidos por lei, ordem legal ou negócio jurídico, com o fim de obter vantagem de qualquer natureza em benefício próprio ou de outrem, mediante infração do dever de salvaguarda, causando prejuízo ao patrimônio administrado:

Pena - reclusão de 1 (um) a 5 (cinco) anos, e multa.

$\S 1^{\circ}$ Compreende-se como prejuízo patrimonial a diminuição do patrimônio, a perda de uma oportunidade fundamentada de obtenção de um incremento patrimonial esperado e a frustração de um fim almejado pelo titular do patrimônio.

$\S 2^{\circ}$ A pena aumenta-se de um a dois terços se o crime for cometido na administração de pessoa jurídica de direito privado.

$\S 3^{\circ}$ A pena será de reclusão de 2 (dois) a 8 (oito) anos, e multa, se o crime for cometido na administração de instituição financeira, assim consideradas aquelas definidas no art. $1^{\circ}$ da Lei n. 7.492, de 16 de junho de 1986.

$\S 4^{\circ}$ Sem prejuízo das penas previstas no caput deste artigo, o juiz poderá aplicar a pena de inabilitação temporária pelo prazo de até 5 (cinco) anos para o exercício do cargo de administrador de pessoa jurídica de direito privado.

$\S 5^{\circ} \mathrm{A}$ ação penal proceder-se-á mediante representação.

18. A proposta de criação do tipo penal de infidelidade patrimonial determinará a readequação de algumas infrações penais que vigem no Direito Penal nacional. Na prática, esse realinhamento acarretará a revogação e a derrogação de alguns crimes contra o patrimônio e contra o sistema financeiro nacional (Lei n. 7.492/1986).

19. O crime de apropriação indébita (art. 168 do CPB) não precisa ser revogado ou derrogado, mas apenas interpretado corretamente. Dessarte, seu raio de incidência típica 
deve ser balizado em consonância com o injusto que o lastreia e em função dos requisitos dogmáticos que o delineiam enquanto infração penal patrimonial.

20. O delito do art. 177 do Código Penal deve ser derrogado tão somente para que o $\S 1^{\mathrm{o}}$ seja suprimido. As condutas tipificadas no $\S 1^{\mathrm{o}}$ do art. 177 do $\mathrm{CPB}$ configuram manifestações societárias abusivas de administração do patrimônio da companhia, mediante a ruptura da obrigação de salvaguarda, e, com a inserção do art. 168-B, tornar-se-ão ociosas, sobretudo porque a Untreue foi projetada como tipo genérico.

21. O crime de gestão fraudulenta e temerária de instituição financeira (art. $4^{\circ}$ da Lei n. 7.492/1986) deve ser revogado. O modelo proposto de administração desleal atende suficientemente às razões político-criminais que justificam a tipificação dos comportamentos infiéis levados a efeito no âmbito das instituições financeiras. Além disso, o tipo penal sugerido para o art. 168-B do Código Penal supera a configuração dogmática atribuída pelo legislador brasileiro ao crime do art. $4^{\circ}$ da Lei n. 7.492/1986.

22. O delito do art. $5^{\circ}$ da Lei n. 7.492/1986 deve ser derrogado para regular exclusivamente as apropriações de coisas alheias móveis e de dinheiro de que o sujeito ativo tem a posse em razão da função desempenhada na instituição financeira, suprimindo-se, em consequência, os comportamentos de "desviar" bem móvel em proveito próprio ou alheio e de "negociar" direito, título ou qualquer outro bem móvel ou imóvel de que tem a posse, sem autorização de quem de direito. Suprimir-se-ia, igualmente, a menção ao art. 25 da Lei n. 7.492/1986, para que o novo tipo penal alcance todos os sujeitos que detêm a posse vigiada de coisa alheia móvel ou de dinheiro por força de sua atividade profissional, e que, ao contrário da administração desleal, não possuem amplo poder de conformação e de disposição do patrimônio alheio.

23. O crime de "caixa dois" (art. 11 da Lei n. 7.492/1986) deve ser ab-rogado, quer porque a manutenção de contabilidade paralela encontra-se integralmente ao alcance típico da infidelidade patrimonial, quer porque o projetado art. 168-B do CPB ostenta inúmeras vantagens dogmáticas em comparação com o seu congênere financeiro. 


\section{REFERÊNCIAS}

ADAMEK, Marcelo Vieira von. Responsabilidade civil dos administradores de S/A (e as ações correlatas). São Paulo: Saraiva, 2009.

ALESSANDRI, Alberto. Reati in materia economica. Torino: Giappichelli, 2012.

ALVIM, Agostinho. Da inexecução das obrigações e suas consequências. 3. ed. atual. Rio de Janeiro: Editora Jurídica e Universitária, 1965.

ANTOLISEI, Francesco. Manuale di diritto penale: parte speciale, I. 15. ed. Milano: Giuffré, 2008.

ARAÚJO JUNIOR, João Marcello de. Dos crimes contra a ordem econômica. São Paulo: RT, 1995.

ASCARELLI, Tullio. Problemas das sociedades anônimas e direito comparado. São Paulo: Saraiva e Cia. Livraria Acadêmica, 1945.

BACIGALUPO, Enrique. Derecho penal económico. Buenos Aires: Hammurabi, 2004.

BACIGALUPO, Silvina. Revista de Derecho Concursal y Paraconcursal, n. 13, Sección Estudios, Editorial Wolters Kluwer, 2. sem. 2010. p. 123.

BAIGÚN, David; DARÍO BERGEL, Salvador. El fraude en la administración societaria: el art. 173, inc. 7, del Código Penal en la órbita de las sociedades comerciales. Buenos Aires: Depalma, 1991.

BAJO, Miguel; BACIGALUPO, Silvina. Derecho penal económico. Madrid: Editorial Centro de Estudios Ramón Areces.

BARBOSA, Henrique Cunha. Responsabilidade de administradores e controladores: o "caso Sadia" numa incursão "guerreiriana" para além do dever de diligência e da ação social. In: CASTRO, Rodrigo Rocha Monteiro de; WARDE JÚNIOR, Walfrido Jorge; GUERREIRO, Carolina Dias Tavares (Coord.). Direito empresarial e outros estudos em homenagem ao professor José Alexandre Tavares Guerreiro. São Paulo: Quartier Latin, 2013.

BARJA DE QUIROGA, Jacobo López. La reforma de los delitos económicos: la administración desleal, la apropiación indebida y las insolvencias punibles. Navarra: Thomson Reuters, 2015.

BATISTA, Nilo. Empréstimos ilícitos na Lei 7.492/86. In: PODVAL, Roberto (Org.). Temas de direito penal econômico. São Paulo: RT, 2000.

BENTO DE FARIA. Código Penal brasileiro comentado: parte especial (arts. 155 a 212). 2. ed. atual. Rio de Janeiro: Distribuidora Record Editora, 1959. v. V.

BENUSSI, Carlo. Infedeltà patrimoniale e gruppi di società. Milano: Giuffrè, 2009. 
BITENCOURT, Cezar Roberto. Tratado de direito penal: parte especial: dos crimes contra a administração pública e dos crimes praticados por prefeitos. 6. ed. São Paulo: Saraiva, 2012. v. 5.

BITENCOURT, Cezar Roberto. Tratado de direito penal: parte especial: dos crimes contra o patrimônio até dos crimes contra o sentimento religioso e o respeito aos mortos. 8. ed. rev. e ampl. São Paulo: Saraiva, 2012. v. 3.

BITENCOURT, Cezar Roberto. Tratado de direito penal: parte geral. 17. ed. São Paulo: Saraiva, 2012. v. 1.

BITENCOURT, Cezar Roberto; BREDA, Juliano. Crimes contra o sistema financeiro nacional e contra o mercado de capitais. 3. ed. São Paulo: Saraiva, 2014.

BITTAR, Carlos Alberto. Os direitos da personalidade. 2. ed. Rio de Janeiro: Forense Universitária, 1995.

BOLEA BARDON, Carolina. Autoría mediata en derecho penal. Valencia: Tirant lo Blanch, 2000.

BREDA, Juliano. Gestão fraudulenta de instituição financeira e dispositivos processuais da lei 7.492/86. Rio de Janeiro: Renovar, 2002.

BRUNO, Aníbal. Direito penal: parte geral; t. $2^{\text {o: }}$ fato punível. Rio de Janeiro: Forense, 2005.

CAHALI, Yussef Said. Dano moral. 2. ed. São Paulo: RT, 1998.

CAMARGO, Antonio Luís Chaves de. Imputação objetiva e direito penal brasileiro. 1. ed. 2. tir. São Paulo: Cultural Paulista, 2002.

CARREÑO AGUADO, Julen A. Caso Enron. In: SÁNCHEZ-OSTIZ, Pablo (Coord.). Casos que hicieron doctrina en derecho penal. 2. ed. 2011

CARRIÓ, Genaro R. Notas sobre derecho y lenguaje. 5. ed. Buenos Aires: Abeledo-Perrot, 2006.

CARVAlHO, Américo Taipa de. Comentários Conimbricense do Código Penal: parte especial, t. II, artigos $202^{\circ}$ a $307^{\circ}$. Dirigido por Jorge de Figueiredo Dias. Coimbra: Coimbra Ed., 1999.

CARVAlHOSA, Modesto. Comentários à Lei de Sociedades Anônimas. 6. ed. rev. e atual. São Paulo: Saraiva, 2014. v. 2.

CARVAlHOSA, Modesto. Comentários à Lei de Sociedades Anônimas. 6. ed. rev. e atual. São Paulo: Saraiva, 2014. v. 3.

CASTILHO, Ela Wiecko V. de. O controle penal nos crimes contra o sistema financeiro nacional: Lei n. 7.492, de 16 de junho de 1986. Belo Horizonte: Del Rey, 2001.

CASTRO MORENO, Abraham. El delito societario de administración desleal (art. 295 CP). Madrid: Marcial Pons, 1998. 
COMPARATO, Fábio Konder. O poder de controle na sociedade anônima. 3. ed., Rio de Janeiro: Forense, 1983.

CORREIA, Eduardo. O crime de abuso de confiança (alguns problemas). RLJ, dir. Manuel Chaves e Castro, ano 93, Coimbra: Coimbra Ed., 1960-1961.

COSTA, Helena Regina Lobo da. A dignidade da pessoa humana: teorias de prevenção geral positiva. São Paulo: RT, 2008.

COSTA JR., Paulo José da. Curso de direito penal. 9. ed. São Paulo: Saraiva, 2008.

COSTA JR., Paulo José da; QUEIJO, Maria Elizabeth; MACHADO, Charles Marcildes. Crimes de colarinho branco. 2. ed. São Paulo: Saraiva, 2002.

CUGAT MAURI, Miriam. La capacidad del derecho penal ante la mala gestión bancaria. La Ley Penal, n. 105, Sección Legislación Aplicada a la Práctica, Editorial Wolters Kluwer, nov.-dez. 2013.

D'AVILA, Fabio Roberto. Ofensividade e crimes omissivos próprios: contributo à compreensão do crime como ofensa ao bem jurídico. Coimbra: Coimbra Ed., 2005.

DELMANTO, Roberto; DELMANTO JUNIOR, Roberto; ALMEIDA DELMANTO, Fabio Machado de. Leis penais especiais comentadas. Rio de Janeiro: Renovar, 2006.

DEMETRIO CRESPO, Eduardo. El significado político del derecho penal económico. In: DEMETRIO CRESPO, Eduardo; CALATAYUD MAROTO, Manuel. Crisis financiera y derecho penal económico. Madrid: Edisofer, 2014.

DÍAZ BARCO, Fernando. El delito societario de administración desleal: sentencias de TSJ y AP y otros Tribunales n. 11/2002. Cizur Menor: Editorial Aranzadi, 2002.

DÍEZ RIPOLLÉS, José Luis. La racionalidad de las leyes penales: práctica y teoría. 2. ed. Madrid: Editorial Trotta, 2013.

EISELE, Andreas. Crimes contra a ordem tributária. 2. ed. rev., atual. e ampl. São Paulo: Dialética, 2002.

EIZIRIK, Nelson. A Lei das S/A comentada: arts. 121 a 188. São Paulo: Quartier Latin, 2011. v. II.

ESTELLITA SALOMÃO, Heloisa. A tutela penal $e$ as obrigações tributárias na Constituição Federal. São Paulo: RT, 2001.

ESTELLITA, Heloisa. Responsabilidade penal dos dirigentes de empresas por omissão: estudos sobre a responsabilidade omissiva imprópria de dirigentes de sociedades anônimas, limitadas e encarregados de cumprimento por crimes praticados por membros da empresa. São Paulo: Marcial Pons, 2017.

FARALDO CABANA, Patricia. Los delitos societarios: incluye la reforma del Código Penal de 2015. 2. ed. Valencia: Tirant lo Blanch: 2015. 
FEIJOO SÁNCHEZ, Bernardo. Crisis económica y concursos punibles. Diario La Ley, $\mathrm{n}$. 7178, Sección Doctrina, 20 de mayo de 2009, año XXX, Ref. D-181, Editorial La Ley.

FELDENS, Luciano. Gestão fraudulenta e temerária de instituição financeira: contornos identificadores do tipo. In: VILARDI, Celso Sanchez; PEREIRA, Flávia Rahal Bresser; DIAS NETO, Theodomiro (Coord.). Direito penal econômico: crimes financeiros e correlatos. São Paulo: Saraiva, 2011.

FELDENS, Luciano; CARRION, Thiago Zucchetti. A estrutura material dos delitos de gestão fraudulenta e temerária de instituição financeira. Revista Brasileira de Ciências Criminais, v. 86/2010, set.-out. 2010.

FERRAZ, Esther de Figueiredo. A codelinquência no direito penal brasileiro. São Paulo: Bushatsky, 1976.

FIANDACA, Giovani; MUSCO, Enzo. Derecho penal: parte general. Bogotá: Temis, 2006.

FOFFANI, Luigi. In: TIEDEMANN, Klaus (Dir.). Eurodelitos: el derecho económico en la Unión Europea. Coordinador de la edición española, Adán Nieto Martín. Cuenca: Ediciones de la Universidad de Castilla-La Mancha, 2004.

FOFFANI, Luigi; NIETO MARTÍN, Adán. Corporate governance y administración desleal: casos y problemas de derecho comparado europeo. Revista Penal, n. 17, España: Tirant lo Blanch, 2006.

FORNACIARI, Gauthama. Gestão fraudulenta e temerária: um estudo jurisprudencial. São Paulo: Saraiva, 2013.

FRAGOSO, Heleno Cláudio. Conduta punível. São Paulo: José Bushatsky, 1961.

FRAGOSO, Heleno Cláudio. Lições de direito penal: a nova parte penal. 11. ed. Rio de Janeiro: Forense, 1987.

FRAGOSO, Heleno Cláudio. Lições de direito penal: parte especial (arts. 168 a 226). São Paulo: José Bushatsky, Editor, 1958. v. 2.

FRAGOSO, Heleno Cláudio. Lições de direito penal: parte especial (arts. 293 a 361). São Paulo: José Bushatsky Editor, 1959. v. 4.

FRAGOSO, Heleno Cláudio. Lições de direito penal: parte especial. São Paulo: José Bushatsky Editor, 1958. v. 1.

FRISCH, Wolfgang; ROBLES PLANAS, Ricardo. Desvalorar e imputar: sobre la imputación objetiva en derecho penal. Barcelona: Atelier, 2004.

GALLEGO SOLER, José-Ignacio. Política criminal en materia de delitos societarios: nuevas tendencias en política criminal, una auditoría al Código Penal español de 1995. Argentina: Euros Editores, 2006.

GALLEGO SOLER, José-Ignacio. Responsabilidad penal y perjuicio patrimonial. Madrid: Editorial B de F, 2015. 
GARCÍA CAVERO, Percy. Aspectos básicos de la reforma del delito de administración fraudulenta de persona jurídica en el Código Penal peruano. In: GÓMEZ-JARA DÍEZ, Carlos; GARCÍA CAVERO, Percy (Ed.). La administración desleal de los órganos societarios. Perú: Ara Editores, 2010.

GARCÍA CAVERO, Percy. Derecho penal económico: parte general. 2 ed. Lima: Editora Jurídica Grijley, 2007. t. I.

GARCÍA CAVERO, Percy. Fraude en la administración de personas jurídicas y delitos contra la confianza y la buena fe en los negocios. Lima: Palestra Editores, 2005.

GARCÍA CAVERO, Percy. La responsabilidad penal del administrador de hecho de la empresa: criterios de imputación. Barcelona: Bosch, 1999.

GOMES, Mariângela Gama de Magalhães. Teoria geral da parte especial do direito penal. São Paulo: Atlas, 2014.

GÓMEZ-JARA DÍEZ, Carlos. ¿Límites penales a la remuneración de los administradores? Apuntes sobre business judgment rule, pay for performance y administración desleal. In: Derecho penal económico. Buenos Aires: B de F, 2010.

GÓMEZ-JARA DÍEZ, Carlos. Caso “Argentia Trust”. In: SANCHÉZ-OSTIZ, Pablo. Casos que hicieron doctrina en derecho penal. 2. ed. Madrid: La Ley, 2011.

GÓMEZ-TRELLE, Javier Sánchez-Vera. Administración desleal y apropiación indebida: consecuencias de la distinción jurisprudencial. In: BARJA DE QUIROGA, Jacobo López; ESPINAR, José Miguel Zugaldía (Coord.). Dogmática y ley penal: libro homenaje a Enrique Bacigalupo. Barcelona: Marcial Pons, 2004. t. II.

GONÇALVES, Carlos Roberto. Responsabilidade civil. 16. ed. São Paulo: Saraiva, 2015.

GRACIA MARTIN, Luis. Prolegômenos para a luta pela modernização e expansão do direito penal e para a crítica do discurso de resistência. Porto Alegre: Sergio Antonio Fabris Editor, 2005.

GRECO FILHO, Vicente. Manual de processo penal. 7. ed. São Paulo: Saraiva, 2009.

GRECO, Luís (Coord.). Estudos de direito penal, direito processual penal e filosofia do direito. São Paulo: Marcial Pons, 2013.

GRECO, Luís. Cumplicidade através de ações neutras: a imputação objetiva na participação. Rio de Janeiro: Renovar, 2004.

GRECO, Luís. Um panorama da teoria da imputação objetiva. 4. ed. São Paulo: RT, 2014.

GRECO, Luís; ASSIS, Augusto. O que significa a teoria do domínio do fato para a criminalidade de empresa. In: Autoria como domínio do fato: estudos introdutórios sobre o concurso de pessoas no Direito Penal brasileiro. São Paulo: Marcial Pons, 2014.

GRECO, Luís; LEITE, Alaor E. O que é e o que não é a teoria do domínio do fato sobre a distinção entre autor e partícipe no direito penal. In: Autoria como domínio do fato: estudos 
introdutórios sobre o concurso de pessoas no direito penal brasileiro. São Paulo: Marcial Pons, 2014.

GRECO, Rogério. Curso de direito penal: parte especial. Niterói, Rio de Janeiro: Impetus, 2006. v. III.

GRECO, Rogério. Direito penal: parte especial, introdução à teoria geral da parte especial, crimes contra a pessoa. Niterói: Impetus, 2005. v. II.

HASSEMER, Winfried. Persona, mundo y responsabilidad: bases para una teoría de la imputación en derecho penal. Santa Fe de Bogotá: Editorial Temis, 1999.

HUNGRIA, Nélson. Comentários ao Código Penal. Rio de Janeiro: Forense, 1958. v. VII.

HUNGRIA, Nélson. Comentários ao Código Penal. Rio de Janeiro: Forense, 1958. v. V.

HUNGRIA, Nélson. Comentários ao Código Penal. Rio de Janeiro: Forense. v. 1, t. 2.

HUNGRIA, Nélson. Comentários ao Código Penal: arts. 250 a 361. Rio de Janeiro: Forense. v. IX.

ILHARRESCONDO, Jorge Marcelo. Delitos societarios. Buenos Aires: La Ley, 2008.

JAKOBS, Günther. A imputação objetiva no direito penal. Trad. André Luís Callegari. 2. ed. São Paulo: RT, 2007.

JAKOBS, Günther. Derecho penal: parte general - fundamentos y teoría de la imputación. 2. ed. Madrid: Marcial Pons, 1997.

JESCHECK, Hans-Heinrich; WEIGEND, Thomas. Tratado de derecho penal: parte general. 5. ed. renovada y ampliada. Granada: Editorial Comares, 2002.

JUAN SANJOSÉ, Rafael Juan. La nueva configuración del delito de administración desleal y su concurso con figuras afines. Barcelona: Wolters Kluwer, 2016.

KAUFMANN, Armin. Dogmática de los delitos de omisión. Barcelona: Marcial Pons, 2006.

LAUFER, Daniel. Artigo 25 da Lei n. 7.492/86: problemas de autoria no âmbito jurídicopenal. Rio de Janeiro: Renovar, 2008.

LEÃES, Luís Gastão Pais de Barros. Mercado de capitais e “insider trading”. São Paulo: RT, 1982.

LEITE, Alaor. Dolo e erro nos delitos de infidelidade patrimonial e administração danosa: violação do dever como elemento misto - ora em branco, ora da valoração global do fato do tipo?. In: LOBATO, José Danilo Tavares; MARTINELLI, João Paulo Orsini; SANTOS, Humberto Souza (Org.). Comentários ao direito penal econômico brasileiro. Belo Horizonte: Editora D’Plácido, 2017.

LEITE, Alaor. Domínio do fato, domínio da organização e responsabilidade penal por fatos de terceiros: os conceitos de autor e partícipe na ap 470 do Supremo Tribunal federal. In: 
GRECO, Luís; LEITE, Alaor E. Autoria como domínio do fato: estudos introdutórios sobre o concurso de pessoas no direito penal brasileiro. São Paulo: Marcial Pons, 2014.

LEITE, Alaor; TEIXEIRA, Adriano. O principal delito econômico da moderna sociedade industrial: observações introdutórias sobre o crime de infidelidade patrimonial. Revista do Instituto Brasileiro de Direito Penal Econômico, n. 1, org. Luiz Antonio Câmara, Bibiana Fontella, Florianópolis: Empório do Direito, 2017.

LEITE, André Lamas. Nótulas esparsas sobre o crime de administração danosa no Código Penal português. RBCCrim, v. 97, São Paulo: RT, jul.-ago. 2012.

LONGOBARDO, Carlo. L'infedeltà patrimoniale: profili sistematici e di politica criminale. Napoli: Edizioni Scientifiche Italiane, 2013.

LUISI, Luiz. Os princípios constitucionais penais. 2. ed. Porto Alegre: Sergio Antonio Fabris Editor, 2003.

LUNA, Everardo da Cunha. Capítulos de direito penal: parte geral, com observações à nova Parte Geral do Código Penal. São Paulo: Saraiva, 1985.

LUZÓN PEÑA, Diego-Manuel; ROSO CAÑADILLAS, Raquel. La administración desleal societaria en el derecho penal español. InDret 3 - Revista para el Análisis del Derecho, Barcelona, abr. 2010.

MARINI, Consuelo. Reati in materia economica. Torino: Giappichelli, 2012.

MARQUES, José Frederico. Elementos de direito processual penal. São Paulo: Forense, 1961. v. 1.

MARTÍNEZ-BUJÁN PÉREZ, Carlos. Derecho penal económico y de la empresa: parte especial. 5. ed. Valencia: Tirant lo Blanch, 2015.

MARTÍNEZ-BUJÁN PÉREZ, Carlos. El delito de administración desleal de patrimonio ajeno. Valencia: Tirant lo Blanch, 2016.

MARTÍNEZ-BUJÁN PÉREZ, Carlos. El delito societario de administración desleal. Valencia: Tirant lo Blanch, 2001.

MATA Y MARTIN, Ricardo Manuel. Estructura fundamental del delito de administración desleal. In: QUINTERO OLIVARES, Gonzalo; MORALES PRATS, Fermín (Coord.). El nuevo derecho penal español: estudios penales en memoria del profesor José Manuel Valle Muñiz. Pamplona: Aranzadi, 2001.

MAZZACUVA, Nicola; AMATI, Enrico. Diritto penale dell'economia: problemi e casi. 2. ed. Milano: CEDAM, 2013.

MIRABETE, Julio Fabbrini. Manual de direito penal: parte especial. 13. ed. São Paulo: Atlas, 1998. v. 2.

MOYA BALLESTER, Jorge. Deberes a cargo de los administradores en el derecho comparado: la Ley 14700/2010. Madrid: Editorial La Ley, 2010. 
MUÑOZ CONDE, Francisco. Administración desleal e insolvencia punible: problemas de imputación personal. In: NIETO MARTÍN, Adán. Homenaje al Dr. Marino Barbero Santos: in memorian II. Cuenca: Ediciones de la Universidad de Castilla-La Mancha: Universidad Salamanca, 2001. v. 2 (Homenajes).

MUÑOZ CONDE, Francisco. Problemas de autoría y participación en el derecho penal económico, o ¿cómo imputar a título de autores a las personas que sin realizar acciones ejecutivas, deciden la realización de un delito en el ámbito de la delincuencia económica empresarial?. Revista Penal, Salamanca, n. 9, p. 59-98, jan. 2002.

MUSCO, Enzo. I nuovi reati societari. 3. ed. Milano: Giuffrè, 2007.

NAUCKE, Wolfgang. El concepto de delito económico-político: una aproximación. Madrid: Marcial Pons, 2015.

NIETO MARTÍN, Adán. El delito de administración fraudulenta. Barcelona: Editorial Praxis, 1996.

NORONHA, E. Magalhães. Direito penal. 24. ed. São Paulo: Saraiva, 2003. v. 4.

NORONHA, E. Magalhães. Direito penal. São Paulo: Saraiva, 1997. v. 1.

NORONHA, E. Magalhães. Direito penal. São Paulo: Saraiva, 1997. v. 2.

OLIVEIRA, Eugênio Pacelli de. Curso de processo penal. 12. ed. Rio de Janeiro: Lumen Juris, 2009.

PAGLIARO, Antonio; COSTA JR., Paulo José da. Dos crimes contra a administração pública. 2. ed. São Paulo: Malheiros Ed., 1999.

PARGENDLER. Mariana. Responsabilidade civil dos administradores e "business judgment rule" no direito brasileiro. p. 9. Disponível em: <http://www.migalhas.com.br/arquivos/2015/11/art20151118-08.pdf>. Acesso em: 17 jun. 2018.

PASTOR MUÑOZ, Nuria. La construcción del perjuicio en el delito de administración desleal: a la vez, una reflexión sobre la naturaleza y las premisas del concepto jurídico-penal de patrimonio y sobre sus raíces históricas en la dogmática de la estafa. InDret, 4/2016, Barcelona, 2016.

PASTOR MUÑOZ, Nuria. La determinación del engaño típico en el delito de estafa. Madrid: Marcial Pons, 2004.

PASTOR MUÑOZ, Nuria. La evolución del bien patrimonio en el seno del derecho penal patrimonial y económico. In: SILVA SÁNCHEZ, Jesús-María (Dir.). La teoría del delito en la práctica penal económica. Madrid: La Ley, 2013.

PASTOR MUÑOZ, Nuria; COCA VILA, Ivó. ¿Administración desleal mediante la creación del riesgo de sanciones para el patrimonio administrado? Un análisis dogmático a la luz del art. 252 del Proyecto de Reforma del Código Penal de 4 de octubre de 2013. InDret, 1/2015 - Revista para el Análisis del Derecho, Barcelona, jan. 2015. 
PASTOR MUÑOZ, Nuria; COCA VILA, Ivó. El delito de administración desleal: claves para una interpretación del nuevo art. 252 del Código Penal. Barcelona: Atelier, 2016.

PEDRAZZI, Cesare; COSTA JR., Paulo José da. Direito penal societário. 3. ed. São Paulo: Perfil, 2005.

PEDRAZZI, Cesare; COSTA JR., Paulo José da. Tratado de direito penal econômico: direito penal das sociedades anônimas. São Paulo: RT, 1973. v. I.

PEÑARANDA RAMOS, Enrique. Um novo sistema penal do direito penal: considerações sobre a teoria de Günther Jakobs. Barueri: Manole, 2003.

PIMENTEL, Manoel Pedro. Crimes contra o sistema financeiro nacional: comentários à lei 7.492, de 16.6.86. São Paulo: RT, 1987.

PIMENTEL, Manoel Pedro. Direito penal econômico. São Paulo: RT, 1973.

PINHEIRO, Armando Castelar; SADDI, Jairo. Direito, economia e mercados. Rio de Janeiro: Elsevier, 2005.

PRADO, Luiz Regis. Comentários ao Código Penal: jurisprudência, conexões lógicas com os vários ramos do direito. 11. ed. rev., atual. e ampl. São Paulo: RT, 2017.

RAMOS, Maria Rita Oliveira. Da importância do crime de infidelidade nos crimes contra o patrimônio. Dissertação (Mestrado). Universidade Católica Portuguesa, Porto, 2014.

REALE, Miguel; REALE JÚNIOR, Miguel; FERRARI, Eduardo Reale. Dever de lealdade do administrador na empresa e direito penal. In: Experiências do direito. Campinas: Millenium Editora, 2004.

REQUENA JULIANI, Jaime. Intercambiabilidad de acción y omisión en los delitos de dominio: posición de garante e imputación objetiva. Madrid: Dykinson, 2010.

REQUIÃO, Rubens. Curso de direito comercial. 20. ed. São Paulo: Saraiva, 1995. v. 2.

REQUIÃO, Rubens. Curso de direito comercial. 22. ed. São Paulo: Saraiva, 1995. v. 1.

ROBLES PLANAS, Ricardo (Dir.). La responsabilidad en los delitos especiales: el debate doctrinal en la actualidad. Buenos Aires: B de F, 2014.

ROBLES PLANAS, Ricardo. Garantes y cómplices: la intervención por omisión y en los delitos especiales. Barcelona: Atelier, 2007.

ROBLES PLANAS, Ricardo. Introducción a la edición española: dogmática de los límites al derecho penal. In: Limites al derecho penal: principios operativos en la fundamentación del castigo. Barcelona: Atelier, 2012.

ROBLES PLANAS, Ricardo. La participación en el delito: fundamento y límites. Barcelona: Marcial Pons, 2003.

RODRIGUES, Silvio. Direito civil: parte geral. 24. ed. São Paulo: Saraiva, 1994. v. 1. 
RODRÍGUEZ MOURULLO, Gonzalo. Estudios de derecho penal económico. Navarra: Thomson Reuters, 2009.

ROJAS A., Luis Emilio. El tipo de administración desleal en el derecho penal alemán. Revista Penal, n. 23, jan. 2009.

ROMEIRO, Jorge Alberto. Da ação penal. 2. ed. Rio de Janeiro: Forense, 1978.

ROSAL BLASCO. Bernardo Del. Algunas reflexiones sobre el delito de administración societaria desleal del artículo 295 del Código Penal de 1995. In: QUINTERO OLIVARES, Gonzalo; MORALES PRATS, Fermín (Coord.). El nuevo derecho penal español: estudios penales en memoria del profesor José Manuel Valle Muñiz. Pamplona: Aranzadi, 2001.

ROSS, Stephen A.; WESTERFIELD, Randolph W.; JAFFE, Jeffrey F. Administração financeira. 2. ed. São Paulo: Atlas, 2007.

ROXIN, Claus. Autoría y dominio del hecho en derecho penal. 7. ed. Madrid: Marcial Pons, 2000 .

ROXIN, Claus. Derecho penal: parte general; t. I - fundamentos. La estructura de la teoría del delito. Madrid: Civitas, 1997.

ROXIN, Claus. Derecho penal: parte general; t. II - especiales formas de aparición del delito. Pamplona: Thomson Reuters, 2014.

ROXIN, Claus. Funcionalismo e imputação objetiva no direito penal. Trad. e introdução Luís Greco. 3. ed. Rio de Janeiro: Renovar, 2002.

ROXIN, Claus. Reflexões sobre a problemática na imputação em direito penal. In: Problemas fundamentais de direito penal. Trad. Ana Paula dos Santos Luis Natscherad. 3. ed. Lisboa: Vega, 2004.

SADDI, Jairo. O sistema financeiro e as crises bancárias. In: Temas de regulação financeira. São Paulo: Quartier Latin, 2010.

SALAMA, Bruno Meyerhof; PRADO, Viviane Muller. Operações de crédito dentro de grupos financeiros: governança corporativa como complemento à regulação bancária. In: ARAÚJO, Danilo Borges dos S. F. de; WARDE, Walfrido Jorge (Ed.). Grupos de sociedades: organização e exercício da empresa. São Paulo: Saraiva, 2012.

SALOMÃO FILHO, Calixto. O novo direito societário. 2 ed. São Paulo: Malheiros, 2002.

SALVADOR NETTO, Alamiro Velludo. Direito penal e propriedade privada: a racionalidade do sistema penal na tutela do patrimônio. São Paulo: Atlas, 2014.

SANTOS, Gerson Pereira dos. Direito penal econômico. São Paulo: Saraiva, 1981.

SANTOS, Juarez Cirino dos. Direito penal: parte geral. 4. ed. rev., ampl. Florianópolis: Conceito Editorial, 2010. 
SCHÜNEMANN, Bernd. A chamada "crise financeira": falha sistêmica ou criminalidade globalmente organizada. In: GRECO, Luís (Coord.). Estudos de direito penal, direito processual penal e filosofia do direito. São Paulo: Marcial Pons, 2013.

SCHÜNEMANN, Bernd. Acerca de la cuadratura del círculo en la dogmática del perjuicio de peligro. In: GÓMEZ-JARA DÍEZ, Carlos; GARCIA CAVERO, Percy (Ed.). La administración desleal de los órganos societarios. Peru: Ara Editores, 2010.

SCHÜNEMANN, Bernd. Caso Mannesmann/Vodafone: acusación de administración desleal por infracción de deberes especiales jurídico-societarios. In: GÓMEZ-JARA DÍEZ, Carlos; GARCÍA CAVERO, Percy (Edit.). La administración desleal de los órganos societarios. Peru: Ara Editores, 2010.

SCHÜNEMANN, Bernd. Fundamento y límites de los delitos de omisión impropia. Barcelona: Marcial Pons, 2009.

SCHÜNEMANN, Bernd. La administración desleal de los órganos societarios: el caso Mannesmann. In: GÓMEZ-JARA DÍEZ, Carlos; GARCÍA CAVERO, Percy (Coord.). La administración desleal de los órganos societarios. Barcelona: Atelier, 2008.

SCHÜNEMANN, Bernd. La administración desleal de los órganos societarios: el caso Mannesmann. In: GÓMEZ-JARA DÍEZ, Carlos; GARCÍA CAVERO, Percy (Ed.). La administración desleal de los órganos societarios. Peru: Ara Editores, 2010.

SCHÜNEMANN, Bernd. Sobre el lado subjetivo de la administración desleal. In: GÓMEZJARA DÍEZ, Carlos; GARCÍA CAVERO, Percy (Edit.). La administración desleal de los órganos societarios. Peru: Ara Editores, 2010.

SEGRELLES DE ARENAZA, Iñigo. El delito de administración desleal: viejos y nuevos problemas. La Ley Penal, n. 121, Sección Estudios, Editorial La Ley, $1^{\circ}$ jul./1º ago. 2016.

SEQUEROS SAZATORNIL, Fernando; DOLZ LAGO, Manuel-Jesús. Delitos societarios $y$ conductas afines: la responsabilidad penal y civil de la sociedad, sus socios y administradores. 4. ed. Madrid: Wolters Kluwer, 2017.

SERRANO CAÑAS, José Manuel. La incorporación de la business judgment rule al derecho español: el proyectado art. 226 de la ley de sociedades de capital. La Ley Mercantil, 6, Sección Sociedades, Editorial Wolters Kluwer, set. 2014.

SERRANO TÁRRAGA, Maria Dolores. Los negocios de riesgo y el delito de administración desleal. Actualidad Penal, n. 41, 5-11 nov. 2001.

SESSA, Antonino. Infedeltà e oggetto della tutela nei reati contro la pubblica amministrazione. Napoli: Edizioni Scientifiche Italiane, 2006.

SILVA SÁNCHEZ, Jesús-María. Fundamentos del derecho penal de la empresa. Buenos Aires: B de F, 2013.

SILVA SÁNCHEZ, Jesús-María. La expansión del derecho penal: aspectos de la política criminal en las sociedades postindustriales. 2. reimpr. Buenos Aires: Euros Editores, 2008. 
SILVA SÁNCHEZ, Jesús-María. Tiempos de derecho penal: escritos breves sobre teoría y práctica, vida social y economía. Buenos Aires-Argentina: Euros Editores, 2009.

SILVA, Wilson Melo da. O dano moral e sua reparação. Rio de Janeiro: Forense, 1955.

SILVEIRA, Renato de Mello Jorge. Direito penal empresarial: a omissão do empresário como crime. Belo Horizonte: D’Plácido, 2016 (Col. Ciência Criminal. Coord. Cláudio Brandão. v. 5).

SIQUEIRA, Galdino. Tratado de direito penal. 2. ed. Rio de Janeiro: José Konfino, 1951. t. I.

STAZJN, Rachel. Sistema financeiro: entre estabilidade e risco. Rio de Janeiro: Elsevier, 2011.

TAVARES, Juarez. Teoria do crime culposo. 3. ed. Rio de Janeiro: Lumen Juris, 2009.

TAVARES, Juarez. Teoria dos crimes omissivos. Madrid: Marcial Pons, 2012.

TÓRTIMA, José Carlos. Crimes contra o sistema financeiro nacional. 2. ed. rev., ampl. e atual., inclusive com comentários aos crimes de manipulação de mercado e uso indevido de informações privilegiadas introduzidos pela Lei n. 10.303/2001. Rio de Janeiro: Lumen Juris, 2002.

VERA RIVERA, María Del Carmen. El delito de administración desleal: criterios de política criminal, fundamentación del injusto y análisis de la tipicidad objetiva. Navarra: Editorial Aranzadi, 2016.

VIANA, Eduardo. Dolo como compromisso cognitivo. São Paulo: Marcial Pons, 2017

ZUCCALÀ, Giuseppe. L'infedeltà nel diritto penale. Padova: Cedam, 1961. 